\title{
Breast Cancer and Pregnancy at Sylvanus Olympio Teaching Hospital of Lome -Togo
}

Ameyo Ayoko Ketevi ${ }^{1 *}$, Akila Bassowa ${ }^{2}$, Baguilane Douaguibe ${ }^{1}$, Dede Regine Diane Ajavon ${ }^{3}$, Alessi Andele ${ }^{1}$, Togbui Seddoh $^{1}$, Gnama Nawa ${ }^{1}$, Kodjo Fiagnon ${ }^{1}$, Abdoul-Samadou Aboubakari ${ }^{4}$

${ }^{1}$ Department of Gynecology and Obstetrics, Sylvanus Olympio Teaching Hospital, Lome, Togo

${ }^{2}$ Department of Gynecology and Obstetrics, Campus Teaching Hospital, Lome, Togo

${ }^{3}$ Department of Gynecology and Obstetrics, Regional Hospital center, Kara, Togo

${ }^{4}$ Department of Gynecology and Obstetrics, Kara Teaching Hospital, Kara, Togo

DOI: $10.36348 /$ sijog.2020.v03i12.004

| Received: 29.11 .2020 | Accepted: 12.12 .2020 | Published: 18.12 .2020

*Corresponding author: Dr. Ameyo Ayoko Ketevi

\section{Abstract}

Introduction: The association of breast cancer and pregnancy is a rare event. The aim of our study is to take stock of this association at the Sylvanus Olympio Teaching Hospital (CHU SO) in Lome, Togo. Methodology: This is a descriptive retrospective study that took place at (CHU SO), Lome, Togo; from January 1, 2014 to December 31, 2018. Results: During our study the frequency of breast cancer and pregnancy was $2.1 \%$. The mean age of the patients was 33.3 years. Multiparas represented $69.2 \%$ of cases. Breast cancer was found in the second trimester of pregnancy in $45.4 \%$. The invasive ductal carcinoma was found $38.4 \%$. Patients had received palliative treatment in $53.8 \%$ of cases. Fifty-three point eight percent $(53.8 \%)$ of the patients were lost to follow-up. Conclusion: Breast cancer associated with pregnancy is difficult. The ideal would be a nationwide subsidy for this disease.

Keywords : breast cancer, pregnancy, Togo

Copyright (C) 2020 The Author(s): This is an open-access article distributed under the terms of the Creative Commons Attribution 4.0 International License (CC BY-NC 4.0) which permits unrestricted use, distribution, and reproduction in any medium for non-commercial use provided the original author and source are credited.

\section{INTRODUCTION}

The association of breast cancer and pregnancy is a rare event defined by the occurrence of breast cancer during pregnancy or during the year following childbirth. The prognosis of these lesions remains unfavorable, if only because of the young age of the patients [1]. Breast cancer is the most common cancer diagnosed during pregnancy and affects about one in 3000 pregnant women [2]. This association makes care difficult. As more and more women choose to postpone childbearing until middle age, the incidence of breast cancer during pregnancy increases and delays in diagnosis and treatment become more common. Therefore, pregnant women with breast cancer are more likely to have larger tumors, positive lymph nodes, metastases and vascular invasion [3]. Symptoms generally appear to be in cancer, overlap, and be masked by physiological changes that occur during pregnancy. So caregivers could easily attribute symptoms of undiagnosed cancer to the pregnancy itself and not conduct further investigation if necessary. In addition, concerns about the exposure of the fetus to the risks inherent in additional examinations (such as ionizing radiation), contrasts and surgical / anesthetic procedures, may make physicians less inclined to proceed immediately to the investigation of these symptoms. [4, 5]. Unfortunately, in many cases, the diagnosis of cancer during pregnancy is delayed [5]. The aim of our study is to take stock of the association of breast cancer and pregnancy at the Sylvanus Olympio Teaching Hospital (CHU SO) in Lome, Togo.

\section{METHODOLOGY}

This is a descriptive retrospective study that took place at Sylvanus Olympio Teaching Hospital in Lome, Togo; from January 1, 2014 to December 31, 2018; either over a period of 5 years; involving 11 pregnant women with breast cancer and 2 who gave birth up to one year with breast cancer. Women with breast cancer who were not pregnant $(\mathrm{n}=585)$, pregnant women who consulted for breast cancer but had no histological evidence $(n=8)$, or those with incomplete dossier $(n=4)$ were not included in our study. Our data were entered, processed and analyzed 
by the software World 2010, Excel 2010. The data was collected using a previously established survey sheet on which we noted for each patient: socio-demographic data, history, breast cancer information, and pregnancy monitoring. Data collection authorization $\mathrm{N} \circ$ 0608/2019 / MSPS / CHU-SO / DIR / DHR / SERV.PERS has been obtained.

\section{RESULTS}

Hospital frequency

During our study 614 patients had consulted for breast cancer among them 13 had consulted for breast cancer and pregnancy, a frequency of $2.1 \%$.

\section{Socio-demographic data}

The mean age of the patients was 33.3 years with extremes of 20 years and 45 years. The $30-35$ age group was the most common (Figure 1).

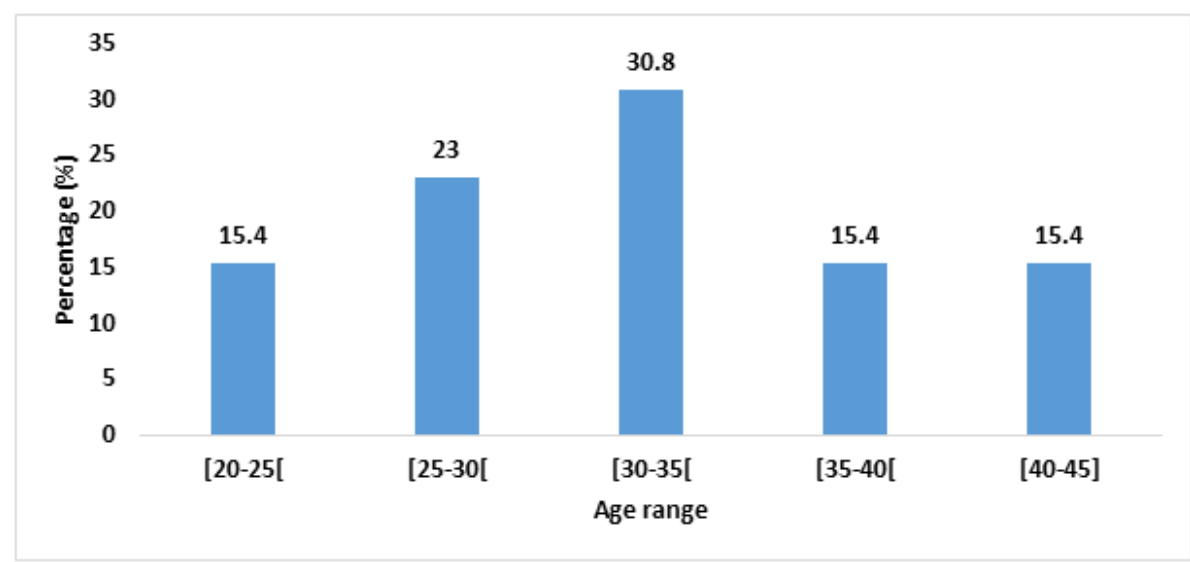

Fig-1: Distribution of patients by age group

In our series, resellers were more represented with a proportion of $30.7 \%$ (figure 2)

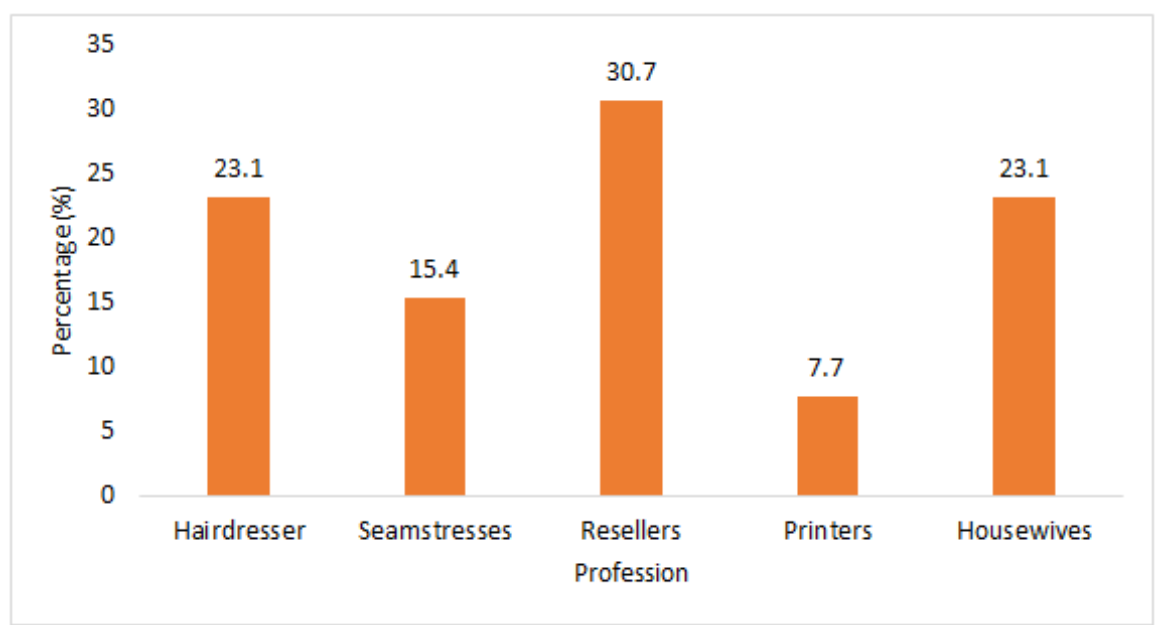

Fig-2: Distribution of patients by profession

\section{Clinical aspects}

The family history was found in 2 patients (15.4\%). Multiparas represented $69.2 \%$ of cases, followed by first-time and nulliparas, in $15.4 \%$ and $15.4 \%$ respectively. In $84.6 \%$ of cases, cancer was discovered during pregnancy and in $15.4 \%$ of cases, the discovery was made after childbirth. Breast cancer was found in the second trimester of pregnancy in a proportion of $45.4 \%$, followed by discovery in the third trimester in $36.4 \%$, and in the first trimester in a proportion of $18.2 \%$. Breast pain was found in a proportion of $15.4 \%$. The tumor was classified T4 in 7 patients $(53.8 \%)$, followed by $\mathrm{T} 2$ in 4 patients $(30.8 \%)$ and $\mathrm{T} 3$ in 02 cases $(15.4 \%)$.
The patients who consulted for breast tumor represented a proportion of $38.4 \%$ (Table I).

Table-I: Breakdown by reason for consultation

\begin{tabular}{|l|l|l|}
\hline & Number & Percentage \\
\hline Breast tumor & 7 & 53.9 \\
\hline antenatal consultation & 4 & 30.7 \\
\hline Breast ulceration & 1 & 7.7 \\
\hline Orange skin & 1 & 7.7 \\
\hline Total & $\mathbf{1 3}$ & $\mathbf{1 0 0}$ \\
\hline
\end{tabular}




\section{Paraclinical aspects}

The ACR5 and ACR4 stages were found in the same proportion in 04 patients each $(30.8 \%)$ followed by ACR 2 stage in 3 patients (23\%), then ACR 3 stage in $15.4 \%$. The invasive ductal carcinoma was found $38.4 \%$ (Table II).

Table-II: distribution of patients according to the results of the anatomo-pathology

\begin{tabular}{|l|l|l|}
\hline & Number & Percentage \\
\hline Invasive ductal carcinoma & 5 & 38.4 \\
\hline lobular carcinoma in situ & 3 & 23.1 \\
\hline invasive lobular carcinoma & 2 & 15.4 \\
\hline Ductal carcinoma in situ & 3 & 23.1 \\
\hline Total & 13 & 100 \\
\hline
\end{tabular}

\section{Supported}

The patients had received palliative treatment in $53.8 \%$ of cases, followed by chemotherapy in $15.4 \%$ of cases and lumpectomy also in $15.4 \%$ of cases.

Eighty -one point eight percent $(81.8 \%)$ gave birth vaginally and in $18.2 \%$ pregnant women had a cesarean section.

\section{Evolution- prognosis}

The patients who had a histo-prognostic grade SBR II represented (61.5\%) followed by the histoprognostic grade SBR III $(30.8 \%)$ and the grade SBRI in $7.7 \%$.

In $84.6 \%$ of cases, the pregnancy was brought to term and in $15.4 \%$ of cases, the pregnancy was terminated. The newborns were all normal weight and had a good APGAR score. Fifty-three point eight percent $(53.8 \%)$ of the patients were lost to follow-up. The remaining $46.2 \%$ were under treatment.

\section{DISCUSSION}

The frequency of breast cancer associated with pregnancy is $2.1 \%$. Our results are similar to those of DIENG et al. in 2018 [6] who found a frequency of $2.9 \%$. In fact, the association of unilateral breast cancer and pregnancy remains a rare event despite the increase in the incidence of this cancer in young women and pregnancies that have become increasingly late [7, 8]. The mean age of the patients was 33.3 years. Anca A. Simionescu et al. in 2020 [9] found an average age of 35 years at the time of diagnosis. Note that $10 \%$ of women under 40 with breast cancer are pregnant at the time of diagnosis [10]. Fifteen point four percent $(15.4 \%)$ of our patients had a family history of breast cancer. Multiparas represented $69.2 \%$ of cases. Anca A. Simionescu et al. in 2020 [9] had also found that breast cancer was associated with multiparity and a shorter duration $(\leq 5$ years) between pregnancies. Breast cancer and pregnancy is generally associated with genetic, environmental, reproductive, and lifestyle factors. Breast cancer was found in the second trimester of pregnancy in a proportion of $45.4 \%$. DIENG et al. [6], found a mean gestational age of 16 weeks with amenorrhea. This discovery of cancer at this stage of pregnancy is due to the fact that women in our community usually wait until the pregnancy comes to a somewhat late term before consulting, especially if there is no associated pathology.

And it is by chance that the tumor is discovered during the first consultation, from where they are referred for better management.

On clinical examination, the tumor was classified as T4 in 07 patients. Our results are similar to those of Anca A. Simionescu et al. [9] who had locally advanced tumors (T3 - T4 and / or N1) in 7 patients (7/12). This diagnostic delay can be explained by the lack of financial means due to the low socio-economic level of our patients. Most of them are resellers $(30.7 \%$ of cases). This probably explains the fact that $53.8 \%$ of patients are lost to follow-up. The invasive ductal carcinoma was the most common $(38.4 \%)$. Patients who had a histopronostic grade SBRII accounted for $(61.5 \%)$. Our results are lower than those of Genin et al. [11] in 2012, where women with breast cancer and pregnancy had invasive ductal carcinoma in $88 \%$ of cases. In fact, the histological types are identical to those encountered outside pregnancy; however the histo-prognostic grade SBR is higher [12], and therefore a poor prognosis. Termination of pregnancy does not improve the prognosis. Its continuation would even be correlated with better maternal survival [7]. This is reassuring and good news in the African context where even therapeutic termination of pregnancy would be poorly understood and badly experienced by the patient. In $84.6 \%$ of cases, the pregnancy was carried to term. With the application of standard treatment, experts consider that the prognosis of cancer during pregnancy is similar to that of non-pregnant patients [13]. The newborns were all of normal weight. This is because there was no chemotherapy before the birth. The chemotherapy in our study was administered to newborn babies (15.4\%). Indeed, during the second or third trimester, adjuvant or neoadjuvant chemotherapy regimens include anthracycline-based treatment, followed by taxanes (paclitaxel and docetaxel) [14-16], and the main known fetal risks include intrauterine growth retardation and a newborn baby small for gestational age [17] 


\section{CONCLUSION}

This study shows that the diagnosis of breast cancer associated with pregnancy is difficult. The therapeutic indications are limited by the constraints of the combination. Our results are pejorative because of the large number of lost to follow-up and the low socioeconomic level; and not the association of breast cancer with pregnancy, which appears to be an independent factor affecting the prognosis. The ideal would be a nationwide subsidy for this disease, especially for pregnant women, for whom free treatment from pregnancy until childbirth has just been decreed by the Togolese government.

\section{REFERENCES}

1. Mathieu, E., Merviel, P., Barranger, E., Antoine, J. M., \& Uzan, S. (2002). Breast cancer and pregnancy: review of the literature. Journal de Gynecologie, Obstetrique et Biologie de la Reproduction, 31(3), 233-242.

2. Shlensky, V., Hallmeyer, S., Juarez, L., Parilla, B.V. (2017). Management of breast cancer during pregnancy: are we compliant with current guidelines? AJP Rep. Jan; 7(1): 39-43.

3. Durrani, S., Akbar, S., Heena, H. (2018). Breast cancer during pregnancy. Cureus. Jul 08; 10(7): 2941.

4. de Haan, J., Vandecaveye, V., Han, S. N., Van de Vijver, K. K., \& Amant, F. (2016). Difficulties with diagnosis of malignancies in pregnancy. Best Practice \& Research Clinical Obstetrics \& Gynaecology, 33, 19-32.

5. Andersson, T. M. L., Johansson, A. L., Fredriksson, I., \& Lambe, M. (2015). Cancer during pregnancy and the postpartum period: A population- based study. Cancer, 121(12), 20722077.

6. Dieng, M.M., Ka, S., Thiam, J. (2018). Breast Cancer and Pregnancy Association: About 28 Cases. African Journal of Surgery, 5(1): 44 - 51.

7. Cuvier, C., Ledoux, F., Coussy, F., Espié, M. (2012). Management of breast cancer during pregnancy. The Letter from the Senologist. JanMar; 55: 12-8.
8. Rouzier, R. (2011). Breast cancer and pregnancy. Breast cancer, expert opinion. 5: 23-5.

9. Simionescu, A. A., Horobet, A., Belaşcu, L., \& Median, D. M. (2020). Real-World Data Analysis of Pregnancy-Associated Breast Cancer at a Tertiary-Level Hospital in Romania. Medicina, 56(10), 522.

10. Raccah-Tebeka, B., Jamin, C., Fourchotte, V. (2012). Pregnancy and breast cancer. The Letter from the Senologist, 55: 6.

11. Genin, A. S., Lesieur, B., Gligorov, J., Antoine, M., Selleret, L., \& Rouzier, R. (2012). Pregnancyassociated breast cancers: do they differ from other breast cancers in young women?. The breast, 21(4), 550-555.

12. Dargent, D., Mayer, M., Lansac, J., Carret, J.L. (1999). Breast cancer and pregnancy: about 96 cases. J Gynecol Obstet Biol Reprod; 5: 783-804.

13. Amant, F., von Minckwitz, G., Han, S. N., Bontenbal, M., Ring, A. E., Giermek, J., ... \& Neven, P. (2013). Prognosis of women with primary breast cancer diagnosed during pregnancy: results from an international collaborative study. Journal of Clinical Oncology, 31(20), 25322539.

14. Cardonick, E. H., Gringlas, M. B., Hunter, K., \& Greenspan, J. (2015). Development of children born to mothers with cancer during pregnancy: comparing in utero chemotherapy-exposed children with nonexposed controls. American journal of obstetrics and gynecology, 212(5), 658-e1.

15. Amant, F., Vandenbroucke, T., Verheecke, M. (2015). Pediatric Outcome after Maternal Cancer Diagnosed during Pregnancy. N. Engl. J. Med. 29; 373, 1824: 34.

16. Simionescu, A.A., Median, D. (2015). Chemotherapy for breast cancer during pregnancy and postpartum: a retrospective descriptive study. Farmacia, 63(3): 417- 21.

17. de Haan, J., Verheecke, M., Van Calsteren, K., Van Calster, B., Shmakov, R. G., Gziri, M. M., ... \& Zola, P. (2018). Oncological management and obstetric and neonatal outcomes for women diagnosed with cancer during pregnancy: a 20-year international cohort study of 1170 patients. The Lancet Oncology, 19(3), 337-346. 